\title{
VIRTUOSA, CASTA Y HEROICA. LA MUJER ESPAÑOLA EN EL MELÓLOGO DEL XVIII
}

\author{
MARÍA ANGULO EGEA
}

Universidad San Jorge de Zaragoza

\section{RESUMEN}

Este trabajo analiza la imagen de la mujer española en los escenarios del Setecientos a través de dos significativos melólogos: La casta amante de Teruel, doña Isabel de Segura de Mariano Nifo y La mujer heroica, esposa de Alonso Pérez de Guzmán el Bueno, doña María Alonso Coronel, de Joaquín Barón y Domingo. En ambos monólogos las dos mujeres escapan del esquema habitual de la mujer-doméstica para encarnar un renovado espíritu de mujer fuerte, heroica, patriótica en última instancia; cada una desde posiciones argumentales muy diferentes, pero en ambos casos, protagonistas de piezas en las que aparece una mujer virtuosa que sale fortalecida y dando ejemplo de heroísmo, tras enfrentarse a una situación límite para su equilibrio personal pero también para el de la sociedad. Las singulares características del género melológico permiten al espectador asistir al proceso emocional de estas heroínas, conocer sus debilidades, tribulaciones y descubrir cómo las superan y cuáles son los procesos razonadores por los que pasan. Todo permite y favorece que el teatro juegue una vez más un papel concienciador.

Palabras claves: Melólogo, géneros sentimentales, Ilustración, teatro del Setecientos, valores femeninos, castidad, heroísmo, virtud, patriotismo, emociones.

\section{ABSTRACT}

This paper concerns itself with the onstage image of Spanish women throughout the Eighteenth Century. With this purpose in mind, two particularly significative melologues - Mariano Nifo's La casta amante de Teruel, doña Isabel de Segura and Joaquín Barón y Domingo's La mujer heroica, esposa de Alonso Pérez de Guzmán el Bueno, doña María Alonso Coronel - will be analysed. In both monologues, the two women eschew the ubiquitous «domestic-wife» model so as to impersonate a fresh type of woman: strong, heroic, and ultimately patriotic. Each of them stems from utterly opposed argumentative stances. Yet, both play the part of a virtuous woman who faces an extreme situation, both personally and socially, only to emerge stronger and a living example of heroism. The specificities of the genre allow the spectator to be an eye-witness to the emotional process of such heroines; to get acquainted with their own weaknesses and hardships; and to find out how they get over them, as well as which mental processes they go through. In a nutshell: all aspects promote the moralising and awareness-raising role, so typically characteristic of most theatrical genres.

Key words: Melologue, sentimental genres, Illustration, $18^{\text {th }}$-Century Drama, female values, chastity, heroism, virtue, patriotism, emotions. 
No es fácil explicar el largo proceso que el papel de la mujer ha tenido en la historia de la representación teatral. Hoy, cuando un personaje femenino aparece en el escenario no necesita «interpretarse a sí misma»; pero esto no ha sido así desde siempre. La mujer fue definiendo y evolucionando su postura en la sociedad y en los albores de lo que hoy consideramos teatro moderno, los papeles femeninos se elaboraron como reflejo de esos patrones sociales. Parafraseando la popular frase de la transición, la escena también tuvo que «convertir en normal lo que en la calle ya era normal». Y la primera normalidad era precisamente la de mostrar sus sentimientos en público, frente al público.

Fueron las teorías sensistas del siglo XVIII las que desembocaron en una literatura abierta a la demostración de los sentimientos y a la exteriorización de las pasiones. Una literatura que erigió a la mujer como protagonista, entendiendo en el sexo femenino un a priori de sentimentalidad claro y definidor principal de su carácter.

La expresión de dolor y tristeza a través de las lágrimas de una mujer no sólo conmovía al público sino que para el espectador resultaba más verosímil que el llanto de un hombre, que siempre representaría un síntoma de debilidad después de siglos de un modelo masculino identificado con una virilidad hierática ${ }^{1}$.

La nueva sensibilidad femenina, construida por intelectuales hombres del Setecientos ${ }^{2}$, tenía su eje de actuación en el amor conyugal. El matrimonio fue la institución estructuradora de la sociedad y el deseo amoroso femenino se canalizaba como amor marital y maternal. La mujer era ante todo esposa y madre, o proyecto de tal. La procreación estaba en sus manos y de su fidelidad dependía el orden familiar y social. El amor fuera de estos cauces era reprensible.

Para no generar en los jóvenes modelos morales equivocados, algunos autores quisieron eliminar este sentimiento de las novelas y el teatro si no estaba asociado al matrimonio. Es el caso del periodista y reformador Mariano Nifo $^{3}$ que así se manifestaba en el Diario Extranjero en 1763 en

${ }^{1}$ Sin embargo, las artes del XVIII lograron institucionalizar un modelo de hombre sensible. Ellos también lloraron y se desmayaron en novelas y comedias sentimentales. Algunos se dejaron empapar de sentimentalidad y rompieron con los estereotipos de la masculinidad dando paso a una mayor homogeneización entre sexos, al menos en lo externo y artístico. Un análisis agudo de esta simetría sexual del período ilustrado puede verse en González Troyano (1997). Los caracteres femeninos también asumieron aspectos asociados con los hombres. La mujer marcial fue una realidad, cuando menos literaria, que impulsó una tradición que llegaría a su máxima expresión en el personaje de Carmen, tipo de mujer dominadora e independiente (Álvarez Barrientos, 2006a).

${ }^{2}$ Para la nómina de escritoras del siglo XVIII y sus contribuciones al panorama literario de la época, véase Palacios Fernández (2002).

3 Véase para esta faceta del periodista como «civilizador y educador» Álvarez Barrientos (2006b). 
un artículo significativamente titulado, «Efectos que causa la pasión de amor demasiado exagerada, y por lo común aplaudida en el teatro». El aragonés afirmaba que «el amor (hablo del que puede servir de asunto en una comedia) necesariamente es una pasión criminal, que debería ir siempre acompañada de desgracias hasta el fin, [...] con trastornos e inquietud; esto es, si se pone en el teatro solo para instrucción de los espectadores, corrección de las costumbres, y no para ruina y embeleso de los incautos jóvenes» (p. 166). Nótese, sin embargo, que la representación de tal pasión, cuando lo permitía la censura, era «por lo común aplaudida».

Pero no hay que pensar que el protagonismo de la mujer le permitiera manifestar sus deseos libremente ${ }^{4}$. Esta literatura pedagógica estaba escrita por hombres y esos deseos y esa libertad encerraban una trampa, ya que indefectiblemente se encontraban predeterminados, tutelados, por la mirada masculina de un padre, tutor o esposo. La sensibilidad femenina se mostraba despojada de deseo. Se trataba de una feminidad doméstica, en tanto que la mujer es centro y alma de la familia. El ideal de mujer virtuosa, de conducta pudorosa, privada de toda sensualidad, se impuso en la literatura sentimental de finales del XVIII en España, y el melólogo contribuyó decisivamente en la difusión de este modelo.

La castidad femenina, virtud definida por el Diccionario de Autoridades como aquella que «modera las pasiones de la parte concupiscible en orden a los actos venéreos y deleites carnales» (1734, I, p. 222), es representada por algunas heroínas dieciochescas como sinónimo de pureza moral y sexual, de honestidad, resistencia inquebrantable y fidelidad; valores encaminados a garantizar la perpetuidad de la especie. Una virtud femenina que consigue incluso apaciguar al hombre, vencer desde la contención el impulso y el desorden pasional masculino, y generar una convivencia matrimonial agradable, sustentada en la amistad y el cariño. Al menos éste era el modelo de conducta que se le exigía a las mujeres y así aparecían representadas desde los nuevos géneros sentimentales; féminas que con su trato apaciguaban y dulcificaban al hombre ${ }^{5}$ y que en un momento determinado podían convertirse en objeto de deseo masculino, pero no en sujetos deseosos, capaces de decidir sobre sus afectos.

Mariano Nifo en su traducción de El amigo de las mujeres se basa en «los antiguos, gentes tan racionales y juiciosas como nosotros», para reducir todas las virtudes a dos capitales: «valor en los hombres y castidad en las mujeres». Y añade que la ausencia de esta virtud en las mujeres «ahuyenta todas las demás, que son sus compañeras inseparables, y relativamente a ella se puede decir, que las mujeres son peores o mejores que los hom-

${ }^{4}$ Para las comedias sentimentales del XVIII, véase García Garrosa (1990) y Pataky Kosove (1977); para la novela sentimental, Álvarez Barrientos (1991).

${ }^{5}$ El propio Nifo tiene un sainete con el singular título de El juicio de la mujer hace al marido discreto. 
bres» (1763, pp. 179-180). La mayoría de los autores ilustrados entendían como virtudes innatas en las mujeres el pudor y la castidad, cualidades ambas que aplicaban con naturalidad a su buen hacer conyugal y que permitían asegurar la legitimidad de los hijos y la correcta transmisión del patrimonio (Bolufer, 1998, p. 280).

La novela sentimental parece que generó féminas que, aun siendo protagonistas de las narraciones, desempeñaban papeles semipasivos ${ }^{6}$; las mujeres de los géneros sentimentales dieciochescos, en efecto, observan cómo transcurren los acontecimientos a su alrededor y sólo se muestran decididas o emprendedoras, cuando se trata de defender un matrimonio o de luchar por unos hijos.

En estos asuntos concentran todas sus energías y originan conflictos sociales ocasionales si su elección de esposo no coincide con la de sus progenitores. Durante toda la centuria el rechazo al matrimonio impuesto y de conveniencia, y la apelación a un consenso entre padres e hijos para determinar la unión conyugal fueron reivindicaciones que abanderaban los propios ilustrados, que las entendían como medidas para favorecer la felicidad y estabilidad familiar. De hecho, escasos son los ejemplos literarios de mujeres que hacen prevalecer su deseo conyugal frente al de sus protectores, sin pagar con la muerte; sobre todo, si esta elección supone una unión desigual ${ }^{7}$.

El melólogo dieciochesco cimentó su estructura literaria en la plasmación de esta sentimentalidad moderna, gracias a una fusión de tendencias artísticas: musicales, pictóricas, interpretativas, dramáticas, entre otras. Un género híbrido y singular que supo actualizar los ideales de las tragedias gracias a la exteriorización de los procesos sentimentales de sus protagonistas, que no representaban otra cosa que procesos del pensamiento, actitudes razonadoras. Esta interpretación de las pasiones y sentimientos se conseguía en el melólogo por medio de una expresividad amanerada, patética e intensiva del actor ${ }^{8}$.

Los escritores de melólogos solían indicar, cómo debían interpretarse las escenas, cuáles eran los gestos y ademanes necesarios para cada situa1995).

${ }^{6}$ Para los modelos femeninos en la novela del XVIII puede verse (Álvarez Barrientos,

${ }^{7}$ Dos excepciones destacables las encontramos en la comedia sentimental de Luciano Francisco COMElla DE TÓJAR, El matrimonio secreto, en donde triunfa la unión entre una burguesa acomodada y su criado; y en la novela de Francisco COMELLA DE TÓJAR, La filósofa por amor, cuya singular protagonista, Adelaida, defenderá y conseguirá la felicidad con el esposo que ella ha elegido, a pesar de las diferencias de clase y de la oposición paterna. Para el sugerente modelo femenino que encarna Adelaida en la novela véase la introducción de Joaquín Álvarez Barrientos a su edición de la obra (1995). En cuanto a las mujeres en el teatro del Comella (Angulo Egea, 2002). 274). 
ción, qué tipo de música exigía el momento, cuándo un silencio reflexivo o una significativa pausa debía expresar aquello que las palabras no pueden, o al contrario, daban pie a la evocadora oratoria de un personaje; aún más, diseñaban, figuraban, pequeños y sugerentes cuadros pictóricos, que añadían patetismo al melodrama. Todo ello en el discurso de los personajes, pero sobre todo en las acotaciones.

El dramaturgo se trasformaba en un director de escena y sus anotaciones resultaban vitales para los actores, pero también para el compositor que creaba la música para cada pieza, con el fin ex profeso de que se adecuara a los momentos emotivos del discurso ${ }^{9}$.

Además, el melólogo contaba a su favor con la brevedad del género, que exigía condensar al máximo lo lírico y lo patético del melodrama. De este modo, el espectador podía disfrutar de esta intensidad emotiva sin que le resultara cansina.

Otro aspecto atractivo del género fue la escasez de personajes. Es muy común la pieza de un único personaje, el cual, ante una circunstancia extrema, desnuda su corazón a un público, confidente, que sigue y comprende los altibajos emocionales del protagonista a lo largo del monólogo. Este protagonismo permitía el lucimiento de los actores, por medio de caracteres de intenso dramatismo, como eran los personajes de la tragedia que recuperaba el melólogo para los escenarios burgueses.

El género recoge los paradigmáticos personajes históricos de la tragedia y los acomoda a su nueva expresión sentimental. Entre las mujeres encontramos de nuevo a Lucrecia, Andrómaca, Dido, Ariadna, Policena, Inés de Castro o María Alonso Coronel como modelos femeninos. Esta vez menos sobrenaturales y más humanos gracias a la «visualización» del desequilibrio emocional de estos caracteres que proporcionaba este teatro breve en las situaciones límites que protagonizan. Estos paradigmas femeninos se mantienen intactos como modelos de conductas virtuosas, castas y heroicas, pero que en la viva expresión de sus angustias, miedos, anhelos, rencores, e incluso dudas, se humanizan y acercan al sentir de los espectadores, que convierten a estas heroínas épicas en mujeres ejemplares sí, pero de carne y hueso.

Los melólogos reproducen, como las tragedias, la temática mitológica grecolatina, pero también recogen modelos hispánicos, nacionales, como los que se analizan en este trabajo. Inés de Castro, María Alonso Coronel o Isabel de Segura mostraban conductas virtuosas y valores patrios. Siguiendo la estela de Iriarte, que con su Guzmán «connaturalizó» el gé-

9 José Subirá comenta al respecto del melólogo La casta amante de Teruel que «...aparecía consignada con toda minuciosidad la interpretación requerida en cada momento para la representación, por lo cual la actriz podría salir airosa en su empeño con sólo seguir fielmente lo ordenado por el autor con precisión absoluta» (1949, I, p. 194). 
nero ${ }^{10}$, La casta amante de Teruel, doña Isabel de Segura (1791) de Mariano Nifo o La mujer heroica, esposa de Alonso Pérez de Guzmán el Bueno, doña María Alonso Coronel (1792) de Joaquín Barón y Domingo ${ }^{11}$, realzaban los principios nacionales, y aproximaban las historias a la idiosincrasia española. En cualquier caso, y haciéndonos eco del significativo título del estudio sobre la tragedia de Sala Valladaura (2006), estos melólogos atendían más al amor que a la política. Amor conyugal en uno y maternal en el otro, pero sentimiento amoroso en todo caso. Con la salvedad de que en este período teatral, e histórico, resulta siempre complicado diferenciar en los personajes su imagen pública o política, de la íntima y personal.

\section{IsABel DE SEgura, LA AMANTE DE Teruel}

La historia de los amantes de Teruel había dado ya buenos y variados frutos literarios y el siglo XVIII iba a recoger el testigo aportándole, como es lógico, sus particulares señas de identidad. De todas formas, las piezas teatrales de Suárez de Deza y Ávila, Tirso de Molina y de Pérez de Montalbán seguían representándose en los coliseos dieciochescos (Andioc y Coulon, 1996, p. 619).

En el melólogo, la brevedad de la pieza y los escasos recursos escénicos obligaban, o cuanto menos aconsejaban, que la situación fuese conocida previamente por el público. El trágico amor de esta pareja formaba parte del acervo cultural de la mayoría de los espectadores del Setecientos y esta es una de las razones por las que fue elegido como tema de melólogo por dos dramaturgos. Uno, el citado Mariano Nifo; y otro, el catalán Luciano Francisco Comella. También para estas piezas breves se escogía un momento culminante o determinante de la historia conocida. A menudo, el melólogo se iniciaba en el momento en que estaba a punto de finalizar el drama o el poema, lo que facilitaba que el espectador se situara mejor en el melodrama.

El melólogo La casta amante de Teruel, doña Isabel de Segura se desarrolla en lo que vendría a ser la última escena de Tirso o de Pérez Montalbán. Doña Isabel llora y lamenta su desgraciado amor ante el cuerpo ya sin vida de su enamorado don Diego. La obra de Nifo centra todo

${ }^{10}$ Véase para este melólogo la edición crítica de Alonso Cuesta y de Pallarés Moreno (Iriarte, 1999), además de los estudios de Sánchez Blanco (1988) y del mismo Pallarés Moreno (1993).

${ }^{11}$ En el Catálogo de Herrera Navarro se indica que Joaquín Barón y Domingo era el pseudónimo que utilizaba el poeta salmantino Fray Diego Tadeo González (1993, pp. 218-219), asunto que no queda registrado en la Bibliografía de Aguilar Piñal (I, pp. 532-533). 
su dramatismo en este monólogo final de Isabel ante el cadáver de don Diego.

Muchos son los aspectos modernos que incorpora Nifo a la protagonista aragonesa. El primero, y más evidente, es la elección del personaje femenino para dar cuenta del desgarro amoroso de esta singular historia. El aragonés estaba adaptando, «connaturalizando», en parte el discurso del griego Pigmalión a la escena española. De hecho, cuando escribía doña Isabel de Segura hacía tan sólo un año que había realizado la traducción del Pigmalión (1790) rousseauniano. Las simetrías con la obra francesa son muchas. Nifo sigue de cerca el modelo de melólogo creado por Rousseau, hasta el extremo de que Isabel también se está dirigiendo a un ser inerte, aunque en el otro caso sea una estatua.

Sin embargo, frente a las abstractas divagaciones amorosas de Pigmalión, Isabel de Segura aparece mucho más concreta, más «real», y sus disquisiciones, además de abundar en el tema del amor casto, abordan algunos de los problemas sociales del momento. Esta mujer trae a colación dos asuntos muy debatidos en la época: los matrimonios acordados por los padres para los hijos sin un consenso previo y el valor de las virtudes de los hombres gracias al esfuerzo y al trabajo frente a los honores heredados.

El espíritu reformador de Nifo se pone de manifiesto en las moderadas reivindicaciones de su Isabel de Segura al denunciar la codicia de los progenitores a la hora de establecer acuerdos matrimoniales:

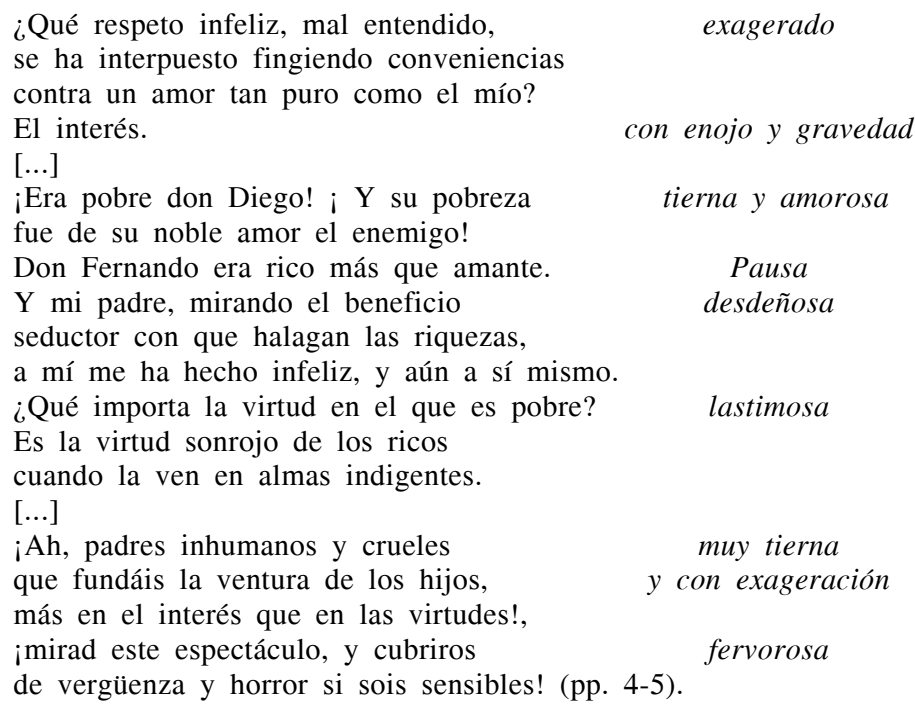

Apela a sus sentimientos para que rectifiquen sus actitudes autoritarias, irracionales e insensibles. Isabel tiene que recurrir al sentimiento religioso 
para superar la situación (como le sucede también a María Alonso Coronel en el melólogo), para no dejarse invadir por el dolor, pero también para perdonar a su padre, a quien juzga con enorme severidad:

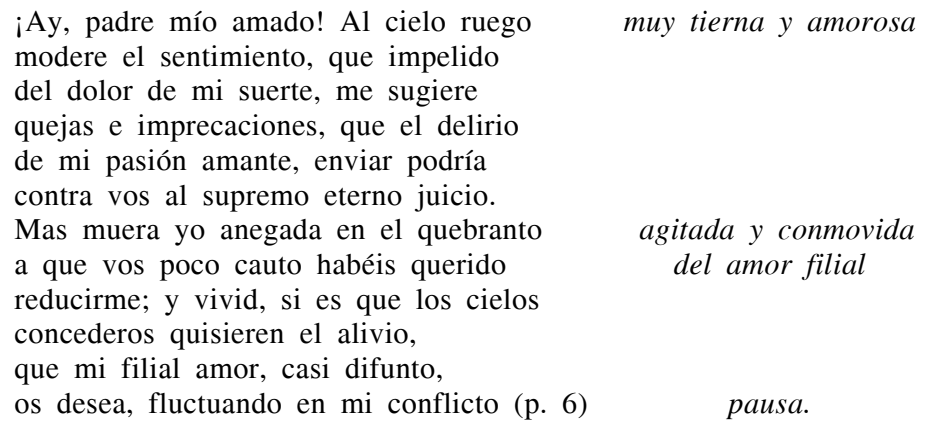

El profundo sentimiento religioso de la protagonista es sin duda un aspecto también destacable, que Nifo liga directamente con la conducta decorosa que defiende Isabel desde el comienzo de su discurso. Nuestra heroína quiere dejar claro en todo momento que el trágico final de su amor no se debe al castigo de una conducta apasionada y desviada del orden moral establecido, ya que su proceder ha sido siempre honesto y virtuoso, modélico, en definitiva, tal y como se le exigía a cualquier mujer. De hecho, en los primeros versos se pregunta el porqué de un final tan terrible para un amor tan inocente y casto como el suyo:

\begin{tabular}{|c|c|}
\hline $\begin{array}{l}\text { ¿Amé a don Diego yo sin recato? } \\
\text { ¿Me amó don Diego a mí, desentendido } \\
\text { de aquellas justas leyes que prescribe, } \\
\text { aún más que el pundonor, el cristianismo? }\end{array}$ & $\begin{array}{c}\text { esforzada con } \\
\text { gravedad }\end{array}$ \\
\hline $\begin{array}{l}\text { No, porque yo le amé como a mi esposo; } \\
\text { no, porque él me estimó con un cariño, } \\
\text { que, no siendo culpable en sus afectos, } \\
\text { fue de la honestidad efecto mismo. }\end{array}$ & con entereza \\
\hline $\begin{array}{l}\text { Yo le amé, sin mirar a las dulzuras } \\
\text { con que el placer se atrae al albedrío. } \\
\text { El me amó por influjo de lo honesto, } \\
\text { y porque acaso hallaba en los sencillos } \\
\text { ardores de mi amor, una inocencia }\end{array}$ & con aire de gravedad \\
\hline
\end{tabular}

Esta reivindicación de un amor casto, que no se ha dejado llevar por los sentidos, es reiterada a lo largo de todo el melólogo. En este caso, castidad asociada a un acentuado espíritu religioso que se divisa tras la figura de Mariano Nifo. Los diferentes escritos del aragonés demuestran su confianza en la religión como instrumento que aglutina e identifica a una nación, así como elemento asociado al buen orden, al funcionamiento co- 
rrecto y civilizado de la sociedad (Álvarez Barrientos, 2006b) ${ }^{12}$. Nifo quiere aportar su visión del modelo de mujer por medio de su paisana turolense. Y para el aragonés el compromiso religioso personal de Isabel de Segura es un valor incuestionable que le permite vencer las pasiones y elaborar un discurso razonable y moderno. Las mismas ideas profesa, como se verá, Joaquín Barón Domingo para su María Alonso Coronel.

Es importante resaltar que la actriz que interpretase a Isabel debería utilizar toda una amplia gama de registros, ya que en el breve tiempo de su presencia en escena tenía que pasar rápidamente por el enojo, la ternura, el desdén, la lástima, el fervor, la agitación, la conmoción, la gravedad y la entereza. Y, además, detenerse en determinados momentos, cuando se señala expresamente «pausa», para acentuar los gestos y expresiones que generan la tensión dramática y mostrar con la mímica, con el cuadro y, sobre todo con ayuda de la música, la desazón profunda que la palabra evoca ${ }^{13}$. Todo un espectro de emociones y sentimientos con los que el público disfrutaba.

El modelo de la Isabel de Comella en Los amantes desgraciados o Los amantes de Teruel (1793) (como se la denomina en la partitura de Blas de Laserna), también conserva el patrón de castidad, exigido a las mujeres, y de obediencia a sus progenitores. Sin embargo, en ningún momento se hace presente el aspecto religioso señalado en el carácter de la protagonista, de un modo tan evidente como en el melólogo de Nifo. La conducta de Isabel es casta porque esa es la moral pertinente; en este pudor y entrega se cifra su honor y su valía. Comportamientos femeninos que, por otro lado, reflejan una tradición porque ya se daban en los textos del Siglo de Oro. Este virtuosismo y castidad no son ni serán patrimonio exclusivo de la imagen de la mujer del período ilustrado, sino que viniendo de atrás este ideal se irá reelaborando a través de los siglos, poniendo al día según las diferentes tendencias ideológicas y artísticas.

Hay una diferencia abismal en la muerte de las dos Isabeles. La casta amante de Nifo muere porque no puede soportar el dolor que le provoca la pérdida de su enamorado don Diego, y decide, en consonancia con su fidelidad, morir siendo suya. Los dos últimos versos concluyen: «y ya que en la vida no, sea en la muerte / nuestro contrato honesto conseguido» (p. 12). Amor trágico y desgraciado, sólo hay posibilidad de unión tras la muerte ${ }^{14}$.

${ }^{12}$ Véase también para comprender la dimensión religiosa de la figura de Mariano Nifo, el apartado titulado «Inquietud y pensamiento religioso» que le dedica al periodista el investigador Enciso Recio en su ya clásico estudio (1956).

13 Señala José Subirá que en los melólogos de Nifo «con alguna frecuencia el vocablo Pausa tenía por objeto señalar allí una interrupción del actor, para que en esos intervalos se intercalaran las respectivas piezas musicales» (1949, I, p. 193). Sin embargo, no se conoce la música de La casta amante de Teruel, ni si llegó a representarse.

${ }^{14}$ Otros ejemplos de amores imposibles en vida y reivindicados tras la muerte aparecen en dos melólogos comellanos: Doña Inés de Castro y El amor conyugal o la 
En cambio, la amante desgraciada de Comella parece morir no sólo de pena, sino por el agravio de la injuria que su ya esposo don Juan levanta contra su honor. Sin honor, no merece la pena vivir. Comella navega entre los esquemas barrocos con una heroína preocupada por su honor y los modelos del Setecientos, que ponen su acento en el valor de la imagen pública. Poco antes se preguntaba Isabel: «¿qué dirán de mí? ¿qué dirá el pueblo?». No sólo había que ser virtuosa, sino parecerlo. Nifo también aborda en su melólogo este aspecto cuando Isabel comenta el sinsentido de seguir adelante con su matrimonio, teniendo en cuenta la desconfianza con la que siempre vivirá su esposo, en este caso Fernando, conociendo el primer amor de ésta y la falsedad sobre la que se concertó su enlace. Por ello entiende que «el medio más decente y más glorioso» es exponer «en aras de la muerte / la vida, del honor el sacrificio» (1818, pp. 9-10).

El melólogo comellano da cuenta de otros asuntos concernientes a su época y muestra un desarrollo más amplio que el de La casta amante de Teruel porque no condensa tanto la acción dramática como Nifo. Los amantes desgraciados empieza justo tras la boda entre Isabel y Juan. La primera acotación presenta a los recién casados recibiendo los parabienes por el enlace, escena muda que da pie a vislumbrar el ambiente en el que vive la protagonista. En esta ocasión, Isabel tiene una interlocutora, su prima Elena, con quien debatirá acerca de la situación en la que se encuentra y sobre su, todavía no olvidado, amante, don Diego. Elena le irá dando la réplica a la protagonista con racionalidad y cordura, mostrando un envidiable espíritu práctico. Aún más, el personaje de Elena resulta en ocasiones más interesante que el de Isabel ${ }^{15}$. En la pieza también aparece «el amante desgraciado», don Diego, que tras conocer la reciente unión de su amada y tomar conciencia de su ya imposible amor, muere en escena, arrastrando con ello a la muerte a la protagonista.

Con esta estructura dramática es lógico encontrar una Isabel más activa que reflexiva. Serán aquí sus actos mucho más que sus palabras los que definan la psicología del personaje. En esta pieza cobran también relieve mecanismos teatrales como las cartas y papeles, los retratos, los engaños y los celos.

Comella por diferentes cauces se separó del melólogo «puro» nacional instaurado por Iriarte, y que siguen de cerca Nifo y, sobre todo, Barón

Amelia. Hace años explicaba el profesor Caldera cómo y por qué se fue pasando de la tragedia neoclásica al drama histórico romántico (1993), argumentos que incluso con mayor rigor pueden trasladarse al melólogo y a los dramas sentimentales en general que también fueron evolucionando hacia los géneros románticos. Coca Ramírez (2000) ha trabajado en cómo se refleja este proceso literario-ideológico en las preceptivas poéticas de la época.

15 Elena, mucho más decidida que su prima, le declara abiertamente su amor a don Diego y trata de aprovechar el matrimonio de Isabel con don Juan, para conseguir el favor de su amado. 
Domingo con su Doña María Alonso Coronel. Es decir, un melólogo unipersonal centrado en los pensamientos y sentimientos de algún héroe hispánico en un momento culminante de su existencia, que coincide en su carácter decisivo con el de la nación. En cualquier caso, la cercanía en fechas con el Pigmalión y el Guzmán, de los melólogos de Nifo y de Barón Domingo, tampoco había dado pie a muchos desarrollos o variantes en un género recién instaurado. De hecho, el primer melólogo de Comella Doña Inés de Castro, de $1791^{16}$, muestra mayor proximidad dramática con el modelo de Nifo y, sobre todo, con la plasmación emocional que hace Barón Domingo de las tribulaciones de la mujer de Guzmán el Bueno. Coincidencias en cualquier caso lógicas, porque los sueños premonitorios o las cartas eran recursos teatrales habituales cuando se quería dinamizar, dar información complementaria, dramatizar, e introducir otra voz en escena, entre otras muchas posibilidades ${ }^{17}$. Sin embargo, el resto de los melólogos comellanos presentan, como se ha comentado, un mayor número de personajes, mitológicos en bastantes casos, muestran argumentos novelescos como en El amor conyugal o La Amelia, versión de una novela de Baculard d'Arnaud (García Garrosa, 2000), y abundan en el enredo teatral.

En todo caso, parece que los actores que interpretaron el melólogo debieron exagerar su actuación hasta lo irrisorio, si atendemos a la recepción que del melólogo aporta Wilhelm von Humboldt en su viaje a España, cuando comenta que en la representación a la que asistió en el Teatro del Príncipe el público «se reía con ganas» ${ }^{18}$. Situación por otro lado curiosa, teniendo en cuenta que los que representaron el melólogo eran actores de primera fila, especialmente alabados por su interpretación en otras piezas similares, como María del Rosario, La Tirana, en el papel de Isabel, Francisca Laborda en el de su prima Elena y José Huerta como Don Diego.

\section{María Alonso Coronel, la esposa de GuzMÁn, El Bueno}

Joaquín Barón Domingo, con su melólogo, aprovechó en 1792 el tirón del Guzmán de Tomás de Iriarte, pero centrándose en el personaje de la madre que sufre ante la muerte de su hijo, aunque como el padre, entiende que debe sacrificar la vida de su primogénito por el bien de la nación. Un año después, José Concha completaría la genealogía con su melólogo, El joven Pedro de Guzmán (1793), en el que el protagonista es el hijo de

${ }^{16}$ Véase mi estudio introductorio a la edición del melólogo de Doña Inés de Castro (Comella, 2005).

${ }^{17}$ Un estudio sobre la importancia y utilidad de las cartas en el teatro puede verse en mi trabajo sobre la producción sentimental, heroica y militar de Luciano Francisco Comella (2006a).

${ }^{18}$ El viajero alemán califica además la pieza de «melodrama estrecho, miserable, frío y $\sin$ efecto» (Humboldt, 1998, pp. 109-110). 
ambos, que asume su muerte en beneficio de su patria. Textos a los que hay que sumar la parodia, con formato también de melólogo, que hiciera Samaniego en 1792 titulada precisamente, Parodia de Guzmán el Bueno. Soliloquio, o escena trágico-unipersonal ${ }^{19}$.

Como se ha señalado con los amantes de Teruel, la historia de Guzmán el Bueno era sobradamente conocida ya en los escenarios del siglo XVIII. La tragedia neoclásica recuperó esta figura medieval como símbolo de los valores patrios, cristianos, frente al otro, en este caso el árabe, y de la felicidad pública por encima del bien particular ${ }^{20}$. Los melólogos reprodujeron estos mismos ideales ilustrados, pero consiguieron, a diferencia de las tragedias de Nicolás Fernández de Moratín y de Cándido María Trigueros, entre otros, acercar estas figuras emblemáticas al público del Setecientos gracias a la expresión de los sentimientos de los personajes. Elaboraron una nueva sentimentalidad que sirvió a su vez para devolverle al público, como actual, el ideal tradicional de mujer virtuosa y heroica.

Los melólogos se apoyaron para expresar esta sentimentalidad en la música. Las piezas de Iriarte y Barón Domingo contaron con excelentes partituras. Una compuesta por el propio Iriarte y la otra por el violinista Melchor Ronzi, que llegaría a director del Teatro de los Caños, la de este último no se conserva.

Además de una singular música, La mujer heroica, esposa de Alonso Pérez de Guzmán el Bueno, doña María Alonso Coronel contó con un padrino de excepción, el Duque de Arión, a quien le dedicó Barón Domingo el melólogo, y en cuya casa particular se representó también la pieza, interpretada por la actriz doña María Coleta García Godínez, según reza en su edición madrileña de la imprenta de la Viuda de Ibarra en $1792^{21}$.

Esta edición contiene la dedicatoria al Duque de Arión, en la que el poco conocido autor declara que su obra la produjo el ocio, con lo que tal vez debía haberse retraído de dedicársela al noble, pero que como

sale a la luz pública en días tan fatales, que a no llevar a la frente su respetable nombre, justamente podría temer fuese despojo de la crítica roedera, que generalmente habita en las guardillas y sótanos subterráneos y hediondos, tanto más temible, cuanto distinguida de aquella juiciosa e imparcial, que nos enseña a corregir nuestros defectos (1792, A3. La cursiva es mía).

Aprovecha Barón Domingo para arremeter contra aquellos pertinaces críticos del teatro del Setecientos. Crítica que se inicia en un interesante prólogo donde se explica el porqué de la calidad humana y de los valores

19 Para esta parodia véase Ríos Carratalá (1999, pp. 95-98).

20 Véase al respecto el citado estudio de Sánchez Blanco Parody (1988).

${ }^{21}$ Los melólogos, por su brevedad y economía de medios, se representaron en muchas ocasiones en casas particulares, como demuestran además los argumentos de algunos sainetes misceláneos de la época. Véase al respecto Angulo Egea (2006b). 
patrios de María Alonso Coronel, y lo que aún es más interesante, cómo ha llevado a cabo el realce y la manifestación de las virtudes de la protagonista dentro del género melológico, disculpando de antemano el uso de algunas licencias teatrales que nada tienen que ver con la realidad, aunque ayuden a explicar el proceso emocional del personaje. Reproduzco el prólogo completo, porque, a pesar de lo extenso, es sumamente interesante para tratar de establecer el concepto de verosimilitud de los patrones sentimentales y dramáticos del melólogo:

Amigo Leyente (que no siempre has de ser Lector, aunque seas Fraile): si yo fuese uno de aquellos famosos escritores, que ocupan las prensas para dar al público unas producciones llenas de instrucción, ejemplo e interés, he aquí que me vería precisamente obligado a tratar ahora del estado actual de nuestros teatros, a censurar las comedias que se representan, y a dar las reglas que se deben observar en su composición. Aquí convendría hablar mal de nuestros desgraciados cómicos, ridiculizar su declamación, y no perdonar ni aun las decoraciones teatrales, y mucho menos lo material de nuestros coliseos, que con razón llaman muchos corrales... Pero ¿para qué he de cansarte con referir lo que haría si puedo concluir más breve, que repetiría lo que plumas más delicadas han escrito desde que se representó la primera comedia en el mundo?

No, amigo (te llamo así porque me mires como tal, y no me tires, según vulgarmente se dice, al codillo), no hallarás en mi proemio nada de eso, pues sólo lo he escrito para que sepas que este drama lo hice por divertirme, así como había de ir a caza de fieras, o a ver la comedia del mágico Brancanelo que para mí todo viene a ser una misma cosa; que en él no verás otra cosa que la contraposición de afectos que sufre la mujer que te represento, y que a mi parecer son propios de su situación; o por si acaso preguntas (como alguno lo ha hecho ya), que en qué está su heroicidad, mira si fue grande la de aquel que en semejante estado decía: Dominus dedir, \&c. (porque no me gusta citar mucho), y me harás justicia.

El estilo he procurado sea acomodado, sin faltar al decoro y nobleza de la persona, al estado en que te la ofrezco; pues si es verdad, que doña María Alonso Coronel se hablaba solo a sí misma en aquel lance (que no lo vi, ni la oí, ni creo que haya quien, a no ser estar loco, hable solo consigo, por afligido que se halle), no es regular anduviese buscando términos retumbantes, frases pomposas, \&c. \&c. \&c. para explicar sus sentimientos.

Por último, los defectos que vayas encontrando, que serán muchos, o disimúlalos, o ríete de ellos, que lo mismo hago yo con los papeles que llegan a mis manos, y mucho más si son de los que se tienen por maestros, careciendo de discípulos; y a Dios, hasta más ver, que aún mi despedida no ha de ser de las de Vale (1792, A4. La cursiva es mía).

De este prólogo conviene destacar algunos aspectos. El primero, el aspecto lúdico que concede a su labor dramática, que la equipara con ir de caza o con ver en el teatro una comedia de magia. Parece que el autor estaba curándose en salud por si se le quería criticar su incursión teatral, y de ahí que se adapte a la retórica de prólogo galeato.

Un segundo aspecto es la descripción que realiza de cómo ha llevado a 
cabo el retrato psicológico de María por medio de la «contraposición de afectos que sufre», adecuados al momento que vive. En consonancia, el autor ha empleado un lenguaje acomodado al linaje de la protagonista, pero al mismo tiempo sencillo, que explicase con el mayor realismo los sentimientos de una mujer en semejante trance y estando sola. No quiere caer en altisonantes términos que pudieran oscurecer al público la compresión del desgarro vital de la heroína. Lo que genera más preocupación a Barón Domingo es la introspección de la protagonista, el hablarse «sólo a sí misma». Asunto que a su entender pone en tela de juicio la verosimilitud de los melólogos unipersonales. Otros autores como Rousseau o Nifo habían resuelto medianamente este aspecto al hacer hablar a los protagonistas con una estatua o a un muerto.

Continúa Joaquín Barón Domingo suministrando información sobre su melólogo y sobre el modelo de mujer que ha querido reflejar en esta pieza por medio de un detallado argumento, previo a los versos. En éste describe el momento concreto del drama de la madre de Pedro y esposa de Alonso Guzmán. María acaba de recibir una carta de su marido donde se le comunica la muerte de su primogénito, cuando esperaba

que Guzmán hubiese proporcionado los medios de su rescate [el de su hijo Pedro secuestrado por el árabe]; por lo cual hace en ella la impresión que es propia en una madre, hasta que, desapasionada, cede a la reflexión, y se vence a sí misma, reprimiendo por medio de una consideración religiosa el desordenado ímpetu que la había constituido en un estado miserable (1792, A4).

En estas breves líneas recoge el autor el modelo femenino de esposa y madre abnegada que tras reflexivos razonamientos logra incluso «vencerse a sí misma». Tras fuertes desequilibrios emocionales María muestra una calma y sobriedad estoicas propias de su calidad moral, de su casto proceder y el de los suyos, así como de su patriotismo ${ }^{22}$. Hay que volver a señalar el aspecto religioso como elemento conformador de un carácter ejemplar de mujer, que en esta pieza ayuda a devolverle el equilibrio emocional a la protagonista «reprimiendo»su primer «ímpetu». Así declara María al enterarse de la muerte de su hijo:
Dadme señor el poderoso auxilio
que necesita la flaqueza mía
en lance tan fatal, en tal conflicto.
¿Dónde están mi valor, mi resistencia
y el varonil esfuerzo que he tenido? (p. 4).

La religión parece suplir la «natural flaqueza femenina» ayudando a que ésta recobre el valor, la resistencia y el esfuerzo que considera propio de

${ }^{22}$ Para el estoicismo como rasgo definidor de los modelos del teatro español del XVIII, véase Busquets (1996). 
los varones. Y es que, en efecto, María no consigue entender lo que en un principio determina como inoperancia de su marido, al que juzga duramente en los siguientes versos:

ya puede estar gozoso

el cobarde Guzmán, porque en los libros

se hará su nombre eterno; pero solo

será para memoria de un delito,

que ha de infamarle siempre, y que de asombro

ha de llenar los venideros siglos.

Con ironía

Esta será tu gloria, tus hazañas,

tus timbres, tu blasón esclarecido

y tu fama; glóriate con ella... (pp. 11-12)

Pero tras estas críticas aparece la duda, la indecisión y la congoja que tanto caracterizan a las protagonistas de melólogos y que serían en cambio impensables en boca de una heroína épica:

Mas no sé lo que siento... desmayadas

mis fuerzas... me parece... que oprimido...

el pecho... el corazón... en mil congojas...

respira ya los últimos suspiros...

¡Oh Dios! ¿me desamparas? ¡Ay esposo!

Ya en dos vidas el triunfo has conseguido.

Ya en dos vidas

Cae en la silla rendida al duro contraste de sus afectos, y entre tanto tocará la orquesta una sonata estrepitosa, que disminuyéndose poco a poco, finalice en un piano expresivo; y concluido, dirá la dama reflexionando con lentitud (p. 12) ${ }^{23}$.

María Alonso de Guzmán es un claro ejemplo de los altibajos emocionales que recogen los melólogos dieciochescos en esa lucha interna por acomodar razón y sentimiento. La propia María, conforme va recuperando el juicio, analiza el estado en el que se cae cuando gobiernan las pasiones:

A que fieros extremos precipita,

cuando no se refrena con el juicio

una pasión, altera las potencias,

introduce en desorden, y a un abismo

de inquietud, sobresaltos y temores

nos conduce, entorpece los sentidos, y obliga a practicar tales errores,

que avergüenzan al mismo que los hizo (1792, p. 13).

${ }^{23}$ Todas estas acotaciones aparecen en la edición en notas a pie de página. Muchos son los afectos que reproducen. Sirvan de ejemplo los siguientes: con viveza; con pausa; levantándose con viveza; con ternura; con expresión; con furor, vuelve sobre sí prontamente, se sienta rendida de dolor, y toca la música un piano lamentable con sordinas, y concluido, sigue la dama reflexionando sobre sus sentimientos con entereza; alegro, y sigue con regocijo; deteniéndose entristecida; sobresaltada. 
Después de todo este proceso interno, la protagonista consigue recuperar su figura de madre ejemplar, porque es capaz de sacrificar a su hijo en beneficio de la patria y de la religión, pero también rectifica y asume su papel de fiel esposa que termina venerando la patriótica decisión de su esposo y bendiciendo su persona.

En resumen, los géneros sentimentales del XVIII, y particularmente el melólogo, difundieron la imagen de mujer abnegada y entregada a la felicidad de los otros (su familia y el Estado), y en esta entrega se cifraba su valía.

Estos ideales femeninos de castidad y virtuosismo no son exclusivos del XVIII sino que recorren toda la literatura, conformando la imagen de la mujer. Pero sí es cierto que el XVIII reforzó esta concepción y vinculó estos valores a las funciones familiares de las mujeres, en tanto que madres, esposas o proyectos de lo mismo.

Y en esta figuración del papel de la mujer en la sociedad, el melólogo tiene un especial protagonismo al presentar en muchas ocasiones una conducta femenina, cimentada en la castidad, pero al tiempo, caracterizada por su fortaleza de espíritu, y una capacidad de decisión generalmente relacionada con asuntos de índole nacional. Este es el caso de Isabel de Segura o María Alonso Coronel. Ambas, al igual que los hombres, luchan por unos principios que consideran justos, por la felicidad pública y por el bien común, sin abandonar los razonamientos y sensibilidad que identificaban su época. Sirven de modelos emblemáticos de mujeres fieles a su condición de esposas y a su patria.

\section{BIBLIOGRAFÍA}

Aguilar PIÑal, Francisco, Bibliografía de autores españoles del siglo XVIII, I, Madrid, CSIC, 1981.

Álvarez Barrientos, Joaquín, La novela del siglo XVIII, Madrid, Júcar, 1991.

—, «El modelo femenino en la novela española del siglo XVIII», Hispanic Review, 63, 1995, pp. 1-18.

—, «Pantomima, estatuaria, muda y parodia en los melólogos (A propósito de González del Castillo)», en Juan Ignacio González del Castillo (1763-1800). Estudios sobre su obra, ed. Alberto Romero Ferrer, Cádiz, Fundación Municipal de Cultura del Ayuntamiento de Cádiz, Servicio de Publicaciones de la Universidad de Cádiz, Grupo de Estudios del Siglo XVIII de Cádiz, 2005, pp. 259-293.

—, «Deseos masculinos, modelos femeninos (la mujer como materia literaria en el siglo XVIII)», en I Congreso Imagen y palabra de mujer (La mujer en la literatura española), ed. Pilar Celma y José Esteban, Valladolid, Fundación Instituto Castellano y Leonés de la Lengua, 2006a (en prensa).

—, «La Ilustración de Francisco Mariano Nifo», Dieciocho, 29.2 (fall), 2006b, pp. 205227.

ANDIOC, René y Coulon, Mireille, Cartelera teatral madrileña del siglo XVIII (17081808), Toulouse, Presses Universitaires du Mirail, 1996, 2 vols. 
ANGulo EgEA, María, «Fingir y aparentar. La imagen de las mujeres a través del teatro sentimental de Luciano Francisco Comella (1751-1812) », Dieciocho, 2002, 25.2 otoño, pp. 281-302.

—, Luciano Francisco Comella (1751-1812). Otra cara del teatro de la Ilustración, Alicante, Universidad de Alicante, 2006a.

- «Los sainetes misceláneos de Luciano Francisco Comella: El día de función nueva, La función casera, El baile deshecho y Juan de la Enreda», en Auflarung. Estudios sobre la Ilustración española dedicados a Hans-Joachim Lope, Cáceres, Universidad de Extremadura, 2006b (en prensa).

BARÓn Domingo, Joaquín, La mujer heroica, esposa de Alonso Pérez de Guzmán el Bueno, doña María Alonso Coronel, Drama unipersonal, Madrid, Imprenta de la viuda de Ibarra, 1792.

BUSQUETS, Loreto, «Modelos humanos en el teatro español del siglo XVIII», en Teatro español del siglo XVIII, ed. Josep Maria Sala Valldaura, Vol I, Universidad de Lleida, 1996, pp. 153-167.

BolufER, Mónica, Mujeres e Ilustración. La construcción de la feminidad en la España del siglo XVIII, Valencia, Institució Alfons el Magnanim, 1998.

CALDERA, Ermanno, «De la tragedia neoclásica al drama histórico romántico: por qué y cómo», Entresiglos II, Bulzoni Editore, 1993, pp. 67-74.

COCA RAMíreZ, Fátima, «La influencia de la 'comedia sentimental' en la poética del 'drama histórico' y de la 'tragedia neoclásica' a principios del siglo XIX en España, Cuadernos de Ilustración y Romanticismo, 8, 2000, pp. 115-130.

Comella, Luciano Francisco, Doña Inés de Castro, Manuscrito Tea-1-23-1 de la Biblioteca Histórica de Madrid, 1791.

—, Los amantes de Teruel. Escena trágico-lírica, 1793, T/24183.

—, Doña Inés de Castro, ed. María Angulo Egea, Germán Labrador López de Azcona y Daniel García Martínez, Salamanca, Grupo de Estudios de Siglo XVIII, 2005.

ENCISO RECIO, Luis Miguel, Nipho y el periodismo español del siglo XVIII, Valladolid, Universidad de Valladolid, 1956.

GARcía GARRosa, María Jesús, La retórica de la las lágrimas. La comedia sentimental española, 1751-1802, Universidad de Valladolid, 1990.

—, «El amor conyugal o La Amelia (1794), de Luciano Francisco Comella y otras adaptaciones dramáticas desconocidas de $\mathrm{F}$ T Baculard d'Arnaud», Boletín de la Biblioteca Menéndez Pelayo, LXXVI, 2000, pp. 193-227.

GonZÁlez TroyANO, Alberto, «Simetría ilustrada y distorsión romántica: lo masculino y lo femenino en el mundo del teatro», en La identidad masculina en los siglos XVIII y XIX, ed. Alberto Ramos Santana, Univ. de Cádiz, 1997, pp. 207-213.

Herrera NAVARro, Jerónimo, Catálogo de autores teatrales del siglo XVIII, Madrid, Fundación Universitaria Española, 1993.

Humboldt, Wilhelm von, Diario de viaje a España 1799-1800, ed. Miguel Ángel Vela, Madrid, Cátedra, 1998.

IRIARTE, Tomás de, Guzmán el Bueno. Escena trágica unipersonal con música en sus intervalos, Juan Antonio Alonso Cuesta y José Pallarés Moreno eds, Algeciras, Instituto de Estudios Campogibraltareños, 1999.

NifO, Francisco Mariano, «Efectos que causa la pasión de amor demasiado exagerada, y por lo común aplaudida en el teatro», Diario Extranjero, XI, Martes 14 de junio, 1763, pp. 163-171.

—, El amigo de las mujeres. Traducido del francés al castellano por..., Madrid, Imprenta de Gabriel Ramírez, 1763.

—, Pigmalión. Monólogo Patético, Madrid, Imprenta de don José de Urrutia, 1790.

-, La casta amante de Teruel, doña Isabel de Segura. Escena patética, Madrid, Imprenta de don Josef de Urrutia, 1791. 
—, La casta amante de Teruel, doña Isabel de Segura. Escena patética, Valencia, Imprenta de Estevan, 1818.

PALACIOS FERNÁNDEZ, Emilio, La mujer y las letras en la España del siglo XVIII, Madrid, Ediciones del Laberinto, 2002.

PAllarés Moreno, José, «Una apuesta teatral de Iriarte: Guzmán el Bueno», en El mundo hispánico en el siglo de las Luces. Actas del Coloquio Internacional «Unidad y diversidad en el mundo hispánico del siglo XVIII», Madrid, Editorial Complutense, 1993, pp. 1001-1014.

Pataky Kosove, Joan, The «Comedia lacrimosa» and Spanish Romantic Drama (17731865), London, Tamesis Books, 1977.

RHOADES, Duane, «Bibliografía anotada de un olvidado género neoclásico en el teatro hispánico», Revista de Literatura, LI, 1989, pp. 191-216.

Ríos CARRATALÁ, Juan Antonio, «Las parodias del melólogo: Samaniego frente a Iriarte», Scriptura, 15, 1999, pp. 89-98.

Sala Valldaura, Josep Maria, Del amor y política: la tragedia neoclásica española, Madrid, CSIC, 2006.

SÁNCHEZ-BlAnCo PARODY, Francisco, «Transformaciones y funciones de un mito nacional: Guzmán el Bueno», Revista de Literatura, 100, 1988, pp. 387-422.

SubIRÁ, José, El compositor Iriarte (1750-1791) y el cultivo español del melólogo (melodrama), Barcelona, CSIC, 1949-1950, 2 vols.

—, Temas musicales madrileños, Madrid, Instituto de Estudios Madrileños, CSIC, 1970.

TÓJAR, Francisco de, La filósofa por amor, ed. Joaquín Álvarez Barrientos, Cádiz, Universidad de Cádiz, 1995. 